\title{
AKTUALISASI NILAI SOSIAL KEMASYARAKATAN 'HANDEP HAPAKAT' DALAM UPACARA KEMATIAN PENGANUT HINDU KAHARINGAN
}

\author{
Oleh:

\section{Budi Purnomo}

\begin{abstract}
Hindu Kaharingan is a belief system adopted by people in the Central Kalimantan. Religious practice of Hindu Kaharingan has provided unique features and characteristics that distinguish it from other religions. The death ceremony is one religious practice of Hindu Kaharingan which consists of long ceremonial stages, starting from the initial stage to the last stage and of course involves the role of various parties and related elements to run well and smoothly. The occurrence of social interaction among Hindu Kaharingan people often involves the attitude of 'handep hapakat' as self-actualization in fostering the values of sincerity, loyalty, help, the spirit of unity, mutual cooperation, and devotion to God Almighty in order to implement religious teaching practices well, smooth and sacred.
\end{abstract}

Keywords: Death ceremony of Hindu Kaharingan; actualization of social values 'Handep hapakat'.

\section{Pendahuluan}

Tulisan ini membahas a ktualisasi nila i sosial kemasyarakatan 'handep hapakat' yang terkait dengan upacara kematian penganut Hindu Kaharingan. Dalam hubungan ini perlu disadari bahwa ada dua nilai yang perlu dijelaskan, yakni 'nilai sosial kemasyarakatan handep hapakat dan aktualisasinya' dan 'upacara kematian penganut Hindu Kaharingan'. Tema ini menarik dikaji apabila dihubungkan bahwa penganut Hindu Kaharingan secara khusus tidak lepas dari rangkaian pelaksanaan upacara-upacara dalam kehidupannya. Upacara kematian bagi penganut Hindu Kaharingan di Kalimantan Tengah pada umumnya juga diyakini sebagai salah satu ritus upacara yang sakral.

Sebagaimana dalam pandangan Durkheim (Haryanto, 2015: 59) yang menjelaskan konsep sakral sebagai salah satu karakteristik agama. Oleh karenanya rangkaian ritual keagamaan bagi penganut agama Hindu Kaharingan mengandung nilainilai kesakralan. Tidak salah tentunya bagi penganut Hindu Kaharingan yang hingga sat ini selalu melaksanakan rangkaian upacara 
kematian jika ada salah seorang keluarga/kerabat yang meninggal dunia. Tata cara ritus upacara kematian penganut Hindu Kaharingan juga tertuang dalam kitab suci Panaturan, yang dalam perkembangannya dilaksanakan ketika ada penganut Hindu Kaharingan yang meninggal dunia. Pelaksanaan ritus upacara kematian penganut Hindu Kaharingan agar berjalan dengan baik dan lancar tentu perlu usaha dan dukungan dari seluruh pihak baik yang berasal dari keluarga duka, kerabat, rohaniwan, dan masyarakat sekitarnya. Dalam hubungan itu, disini akan dijelaskan secara singkat pengertian 'handep hapakat dan nilai sosial kemasyarakatannya', dan 'upacara kematian penganut Hindu Kaharingan'.

Istilah 'handep hapakat' secara etimologis berasal dari bahasa Dayak Ngaju yang terdiri dari dua kata yaitu 'handep' dan 'hapakat'. Apabila masing-masing diartikan maka handep (Iper, 2009: 215) diartikan 'gotong royong'. Sedangkan, hapakat (Iper, 2009: 505) dari kata 'pakat' yang berarti 'pakat; mupakat; setuju'. Dapat diketahui bahwa 'handep hapakat' yang diartikan sebagai tindakan saling gotong royong, saling bantu-membantu dan/atau saling bermupakat.

Selanjutnya, upacara kematian penganut Hindu Kaharingan terdiri dari berbagai rangkaian ritus upacara hingga upacara kematian tingkat terakhir dengan terlaksananya upacara Tiwah. Pelaksanaan upacara kematian penganut $\mathrm{Hindu}$ Kaharingan di beberapa daerah yang ada di wilayah Kalimantan Tengah secara umum memang ada perbedaan satu sama lain. Namun, bagi penganut Hindu Kaharingan perbedaan dalam praktik keagamaan adalah hal lumrah karena menyesuaikan dengan dasa, kala, dan patra masing-masing wilayah tersebut sehingga memunculkan kebiasaan yang tidak sama dalam pelaksanaan suatu praktik keagamaan yang berlangsung dari dulu hingga kini. Sebagaimana dikemukakan Bakker (dalam Snijders, 2004: 58) bahwa wilayah kebudayaan dapat berbeda-beda menurut jenis nilainya yang mana hal tertentu mendapat nilai bagi manusia dari segi biologis atau dari segi ekonomis atau sosial, dari segi estetis atau religius.

Nilai sosial masyarakat terdiri atas konsepsi-konsepsi yang hidup dalam alam pikiran, ide, pandangan hidup sebagian besar warga masyarakat (dalam hal ini penganut Hindu Kaharingan) mengenai hal-hal 
yang harus mereka anggap amat bernilai atau baik dalam hidup untuk diteruskan kemudian kepada generasi penerus. Dengan begitu, nilai sosial kemasyarakatan 'handep hapakat' dalam tulisan ini dapat dimengerti sebagai: nilai mupakat, nilai persatuan, nilai gotong royong, nilai tolong-menolong untuk melaksanakan upacara kematian penganut Hindu Kaharingan agar berjalan dengan baik, sakral dan lancar. Nilai-nilai 'handep hapakat' diproyeksikan sebagai hubungan sosial kemasyarakatan dalam kehidupan penganut Hindu Kaharingan secara khusus dituangkan dalam pelaksanaan ritus upacara kematian oleh keluarga duka yang ditinggalkan.

\section{Pembahasan}

\subsection{Konteks Upacara Kematian Penganut Hindu Kaharingan}

Menurut Bacon (dalam Timo, 2010: 88), dia percaya bahwa tidak satupun manusia yang takut terhadap kematian. Kematian tidak perlu ditakuti karena kematian adalah hal yang pasti di mana semua manusia akan mengalaminya, hanya waktu, tempat dan situasi yang tidak sama datangnya kematian menjemput setiap manusia.

Kematian tentu sebagai suatu hal yang tidak dapat dihindari oleh manusia dan pasti akan dialami entah kapan dan dimana masih menjadi misteri. Kematian mengundang kesedihan dan duka bagi keluarga yang ditinggalkan. Namun, hal yang pasti bahwa kehidupan manusia di dunia hanya bersifat sementara dan fana. Bagi penganut Hindu Kaharingan sendiri perihal kematian adalah jalan yang sudah ditentukan untuk kembali menyatu kepada Ranying Hatalla (Tuhan Yang Maha Esa).

Kitab suci Panaturan dalam narasinya menyebutkan salah satu penyebab terlaksananya ritus upacara kematian bagi umat manusia di dunia. Keyakinan penganut Hindu Kaharingan bahwa manusia di dunia adalah keturunan 'Raja Bunu' yang mendapatkan takdir mengalami kematian di Pantai Danum Kalunen/Lewu Injam Tingang (dunia fana). Hal tersebut sebagaimana bunyi sabda Ranying Hatalla (Tuhan Yang Maha Esa) kepada Raja Bunu dan keturunannya dalam kutipan Panaturan (2017: 107-108), yaitu:

"Hete RANYING HATALLA bapander panjang umba Raja Bunu, tuh bitim palus panarantang aim, akan ilaluhan kareh manyuang Batang Petak ije jadi injapaKU hanyak inyewutKU jete Pantai Danum Kalunen tuntang panarantang aim te dapit jeha puna bagin matei". 
Terjemahan:

Dengan panjang lebar RANYING HATALLA berfirman kepada Raja Bunu, firmanNYA: Untuk engkau ketahui Raja Bunu, bahwa engkau dan semua anak keturunanmu akan aku turunkan mengisi permukaan tanah bumi yang telah KUciptakan dan AKU sebutkan itu kehidupan, serta bagi anak keturunanmu nantinya, ia kembali kepadaKU melalui kematian. (Pasal 29, Ayat 4)

Bunyi kutipan ayat pasal di atas menegaskan bahwa Raja Bunu dan keturunannya yang diturunkan ke dunia akan mengalami proses kelahiran, menjalani kehidupan hingga kematian kelak ketika di dunia. Adapun di kalangan penganut Hindu $\mathrm{K}$ aharingan sendiri memang meyakini dirinya sebagai generasigenerasi penerus keturunan Raja Bunu yang diturunkan Ranying Hatalla (Tuhan Yang Maha Esa) di masa lampau. Keyakinan tersebut dipercaya hingga saat ini dan penganut Hindu Kaharingan tetap setia menjalankan ajaran-ajaran kepercayaan leluhur di masa lampau tersebut. Ajaran yang terkandung dalam kitab suci Panaturan dijadikan petunjuk dan pedoman hidup bagi penganut Hindu Kaharingan yang menjalani kehidupan di dunia baik ajaran kepercayaan kepada Ranying Hatalla (Tuhan Yang Maha Esa) dan manifestasinya, pengamalan etika, moralitas, serta tata cara pelaksanaan ritual upacaranya dan banyak lagi upacara-upacara lainnya.

Konteks praktik upacara kematian keagamaan penganut Hindu Kaharingan salah satunya adalah bagian dari tradisi atau kebiasaan baik perorangan maupun sekelompok orang yang masih memegang ajaranajaran kepercayaan leluhur (tatu hiang). Durkheim (sebagaimana dikutip Vigilant \& Williamson, 2007: 148) mendefinisikan agama sebagai seperangkat kepercayaan dan praktik-praktik bersangsi yang mendasari perkembangan moral komunitas. Pernyataan Durkheim jelas memberikan alasan yang memperkuat bahwa penganut Hindu Kaharingan kini masih berisikan kepercayaan agama yang absolut artinya ajaran keagamaan Hindu Kaharingan bersifat dinamis dan fleksibel baik di masa lampau, masa kini dan masa yang akan datang dalam menjalankan ritus-ritus praktik keagamaan dengan fungsinya tersendiri yang juga mempelajari konteks sosial dalam kehidupan masyarakatnya.

Hal tersebut terbukti karena praktik keagamaan yang dilakukan penganut Hindu Kaharingan sebagian besar terdapat dan berdasar atas petunjuk, pedoman dan ajaran yang 
diajarkan secara lisan maupun tertulis dari leluhur/nenek moyang (tatu hiang), bahkan termasuk di dalamnya yang termuat dan dinarasikan kitab suci Panaturan. Namun, tentu juga ada beberapa tata cara, budaya, kebiasaan yang telah membudaya dalam kehidupan masyarakat di Kalimantan Tengah tetap dilaksanakan sebagai kekayaan identitas, kearifan lokal, adat budaya dari nilai-nilai luhur yang diwariskan oleh nenek moyang sejak dahulu kala dan kini tetap diimplementasikan oleh penganut Hindu Kaharingan .

Terkait upacara kematian yang dilaksanakan penganut $\mathrm{Hindu}$ Kaharingan, maka kitab suci Panaturan menyebutkan pula perihal rentetan upacara yang dilaksanakan oleh keturunan Raja Bunu ketika terjadinya kematian dan tertuang dalam kutipan ayat Panaturan (2017: 129) berikut.

"Sahelu bara RANYING HATALLA malaluhan Raja Bunu ewen hanak nanturung Pantai Danum Kalunen, hete IE manyahuan ewen malalus Tiwah Suntu intu Lewu Bukit Batu Nindan Tarung, Rundung Kereng Liang Bantilung Nyaring, awi jetuh kareh ije manjadi suntu akan panakan Raja Bunu, jete ampin jalan ewen te buli haluli manalih IE."

Terjemahan:

Sebelum RANYING HATALLA menurunkan Raja Bunu sekeluarga menuju Pantai Danum Kalunen, disitu IA me n y r u $\mathrm{m}$ e re k a melaksanakan Tiwah Suntu di Lewu Bukit Batu Nindan Tarung, sebab ini nanti yang menjadi contoh untuk keturunan Raja Bunu, bagaimana tata caranya mereka itu kembali dan dating menyatu kepadaNYA. (Pasal 32 ayat 2)

"Limbah te tinai RANYING HATALLA palus ma-atuh hayak manukas, eweh-eweh je menggawie kareh akan panakan Raja Bunu te, amun ewen malalus ampin jalan ewen buli manalih IE, iete ma-atuh bara katamparae, palus kahapus gawie."

Terjemahan:

Setelah itu RANYING HATALLA mengatur lagi dan menetapkan s i a p a - s i a p a y a n g melaksanakannya bagi keturunan Raja Bunu dan kalau mereka melaksanakan tata cara kembali kepadaNYA mulai dari a walnya hingga a khir pelaksanaannya. (Pasal 32 ayat 3)

Kutipan ayat kitab Panaturan tersebut menjelaskan adanya tata cara terkait pelaksanaan upacara kematian oleh Raja Bunu dan keturunannya di dunia. Rangkaian tata cara upacara kematian penganut Hindu Kaharingan diketahui bukanlah proses yang singkat apabila dikaji lebih mendalam baik dari segi 
rukun kematian tahap awal hingga tahap terakhir. Oleh karena itu, apabila ada salah seorang penganut Hindu Kaharingan yang meninggal dunia maka wajib diupacarakan sesuai tata cara setempat dengan rangkaian tata cara ritus kematiannya di masing-masing daerah.

Penjelasan Mariatie, dkk (2016: 106) menyatakan agama Hindu Kaharingan ritual kematian tidak hanya sampai pada ritual penguburan, namun masih memiliki beberapa tahapan lagi menyesuaikan dengan tradisi masing-masing daerah. Selanjutnya Mariatie, dkk (2016) menyebutkan upacara kematian menurut agama Hindu Kaharingan terdiri dari tiga tahapan dimulai dari upacara penguburan, balian tantulak ambun rutas matei, dan upacara tiwah. Sedangkan, menurut Kencong (dalam Tim, 2009) prosesi upacara kematian menurut Hindu Kaharingan diuraikan dari upacara penghembusan nafas terakhir, upacara namean liau haring kaharingan ke dalam peti jenazah, upacara penguburan, balian tantulak ambun rutas matei, dan upacara terakhir yaitu Tiwah.

Pada dasarnya, pelaksanaan rangkaian rukun upacara kematian penganut Hindu Kaharingan yang berbeda-beda di masing-masing wilayah di Kalimantan Tengah bukan menjadi persoalan besar karena memberikan coraknya sendiri. Keanekaragaman yang ada terkait tata cara kematian masyarakat di Kalimantan Tengah tetap membuat penganut Hindu Kaharingan bersatupadu dalam pemahaman dan bersaudara (penyang hinje simpei) menjalani kehidupan sosial masyarakat.

Upacara kematian penganut Hindu Kaharingan yang dibahas dalam tulisan ini secara khusus yang dilaksanakan oleh masyarakat suku Dayak Ngaju. Adapun penjelasan terkait rangkaian upacara kematian tersebut apabila dirunut maka dapat dimulai ketika prosesi almarhum telah menghembuskan nafas terakhirnya. Ketika ada salah seorang penganut Hindu Kaharingan meninggal dunia akan dilakukan memukul gong (manitih/nitih) bila yang meninggal laki-laki dibunyikan sebanyak 7 (tujuh) kali dan perempuan 5 (lima) kali. Proses selanjutnya dilakukan dengan memandikan jenazah yang terdiri dari beberapa langkah-langkah. Memandikan jenazah diikuti pula dengan pelafalan mantramantra/tawur sehingga dalam hal ini biasanya keluarga duka memohon bimbingan dari rohaniwan/orang 
yang berpengalaman yang memahami tata cara upacara kematian yang benar.

Terkait langkah tersebut dijelaskan Mariatie, dkk (2016: 108), yaitu:

Pertama-tama yang dilakukan dalam merawat jenazah adalah mengambil air menggunakan telapak tangan disertai dengan mengucapkan mantra: "Tuh anu ..... (nama almarhum) aku mampandui ikau hapa danum ije barasih danum Pantis Rangkan, Bulau Rangkan Hintan mangat ikau tuh Habalitan Bulau Hintan Buli Nyembang Ranying Hatalla Langit buli Lewu Tatau Ije Dia Rumpang Tulang Rundung Raja Kamalesu Uhate Manyak Pelek Uluh Tingang Tatu Hiang". Setelah itu, air diusapkan ke jenazah, karena yang pertama tercipta dari manusia yaitu mata. Kemudian diikuti dengan menyirami seluruh anggota badan jenazah sampai merata dan memandikan jenazah sampai benar-benar bersih.

Prosesi selanjutnya, diikuti dengan mendandani jenazah yang dalam hal ini ada hal-hal penting yang perlu diperhatikan baik posisi dimana meletakkan jenazah serta penyiapan sarana-sarana yang diberikan pada jenazah. Setelah itu, dilanjutkan dengan pembuatan peti jenazah (raung), prosesi manyaluh raung, dan memasukkan jenazah ke dalam raung. Menurut Mariatie (2016: 111-
112) bahwa prosesi upacara penguburan (pemakaman) dilaksanakan 2 (dua) tahap, yaitu:

1. Mampalua raung bara huma (mengeluarkan peti jenazah dari rumah duka;

Sebelum peti jenazah dibawa keluar rumah duka terlebih dahulu disiapkan sarana: danum karak (air yang dicampur dengan kerak nasi), tampung papas (sarana mamapas yang t e rdiri dari d a $\mathrm{n}$ andong/sawang gugur dan daun kayu tungkun), beras tawur (beras berwarna merah dan kuning karena dicampur dengan kunyit), giling pinang, rukun tarahan, bua baluh (kendi berisi air), sumbu (lampu teplok). Setelah semua sarana siap maka peti jenazah dibawa ke depan pintu rumah dengan posisi kepala jenazah apabila laki-laki maka kepalanya ke arah luar dan perempuan dalam posisi ke dalam rumah. Dilanjutkan dengan mamapas raung (mensucikan peti jenazah) y ang disertai pelafalan $m$ antra, kemudian petije nazah diayun-ayunkan keluar masuk di tengahtengah pintu sebanyak 7 (tujuh) kali apabila yang meninggal laki-laki dan untuk perempuan sebanyak 5 (lima) kali disertai dengan pemukulan gong. Bila peti jenazah sudah keluar, adapun kendi yang berisi air langsung dipecahkan di depan pintu rumah supaya sial habis dibawa. Peti 
jenazah langsung dibawa ke tempat peristirahatan terakhir.

2. Peti jenazah berada di pemakaman (Bukit Pasahan Raung Kereng Rabia Nyapenda Lunuk Tarung)

a. Menyerahkan jenazah kepada Raja Entai Nyahu (Dewa penjaga kuburan)

b. Peti jenazah diletakkan di atas liang kubur dan ditopang galangan kayu

c. Acara penyerahan jenazah kepada Raja Entai Nyahu dipimpin oleh Basir/Rohaniwan dilaksanakan dengan cara manawur (menabur beras tawur) yang telah disiapkan, bertujuan untuk memberitahukan dan agar almarhum diterima menyatu dengan Ranying Hatalla.

d. Acara pemakaman (biasa diiringi dengan nyanyian Kandayu Metuh Mangubur)

e. Setelah prosesi penyerahan jenazah kepada Raja Entai Nyahu (Dewa penjaga kuburan) langsung diadakan upacara pemakaman

f. D a l a u p c a r a pemakaman peti jenazah dimasukkan ke liang kubur dengan tanah dan langsung ditancapkan Sampalak (Batu nisan) dilanjutkan dengan menghidupkan dan mematikan lampu tembok yang dibawa sebanyak 3 (tiga) kali

berturut-turut disertai pelafalan mantra oleh Basir/Rohaniwan.

3. Balian Tantulak Ambun Rutas Matei

Pelaksanaan prosesi ini dilangsungkan setelah 3 (tiga) hari dari proses pemakaman Liau Haring Kaharingan (y a n g m e n i ng gal d u n i a ) dimakamkan, setelah itu barulah diadakan upacara Balian Tantulak Ambun Rutas Matei. Pelaksanaan Balian Tantulak Ambun Rutas Matei bertujuan menghapus segala sial dan pantangan di dalam kehidupan yang disebabkan oleh adanya kematian di antara kehidupan mereka sekaligus mengantar arwah Liau Haring Kaharingan menuju ke Lewu Bukit Nalian Lanting, Rundung Kereng Naliwu Rahan (tempat persinggahan sementara untuk menuju ke Lewu Tatau).

4. Upacara Tiwah

Upacara Tiwah adalah upacara suci, kewajiban yang mutlak dilaksanakan dan merupakan hutang akibat kematian salah s e orang keluarga . Pelaksanaan Tiwah melalui proses yang cukup panjang dan memakan biaya yang besar dan waktu hingga satu bulan atau lebih. Prosesi Tiwah bertujuan untuk menghantarkan Liau Haring Kaharingan agar dapat kembali menyatu bersama 
Ranying Hatalla dan mencapai Lewu Tatau.

Rangkaian pelaksanaan ritus upacara kematian masyarakat suku Dayak Ngaju memberikan gambaran singkat terkait praktik keagamaan yang dijalankan penganut Hindu Kaharingan. Apabila dilihat dalam dinamika pelaksanaan ritus upacara kematian, prosesi praktik keagamaan ini sudah berlangsung sejak lama. Di masa kekinian bahwa penganut Hindu Kaharingan masih tetap meyakini untuk kembalinya roh manusia menyatu kembali pada Ranying Hatalla adalah hanya melalui prosesi upacara kematian yang baik dari tahap awal hingga tahap terakhir pelaksanaannya yaitu ritus upacara Tiwah. Beberapa daerah lain upacara tingkat terakhir dikenal Nyorat, Wara, Tambak, Bontang dan sebagainya.

Pada zaman modern, tentunya secara konsep pelaksanaan ritus kematian penganut $\mathrm{Hindu}$ Kaharingan perlu penggalian nilainilai kearifan lokal nenek moyang (tatu hiang) yang hidup di bumi Kalimantan, dengan kesadaran sikap 'handep hapakat' yang juga memerlukan rasa kebersamaan, kesetiaan, kejujuran, dan percaya kepada Ranying Hatalla (Tuhan Yang Maha Esa). Teraktualisasinya nilainilai sosial kemasyarakatan 'handep hapakat' sebagai bentuk lahirnya semangat persatuan/mupakat dan terciptanya gotong royong dalam kehidupan sosial bermasyarakat yang perlu diajarkan kepada generasigenerasi muda Hindu Kaharingan sekarang dan masa mendatang.

\subsection{Nilai Sosial Kemasyarakatan dan Aktualisasi 'Handep Hapakat'}

Aktualisasi 'handep hapakat' saat salah seorang penganut Hindu Kaharingan meninggal dunia telah berlangsung sejak lama. Entah kapan kebiasaan ini dimulai namun menurut informan salah seorang tokoh Hindu $\mathrm{K}$ aharingan mengatakan bahwa 'handep hapakat' berlaku untuk semua orang atau penduduk baik itu penduduk asli maupun penduduk pendatang yang baru menetap maupun yang sudah lama menetap di bumi Kalimantan Tengah khususnya. Mereka berpendapat bahwa yang ada di wilayah tersebut adalah semua saudara tidak memandang suku, ras, dan agama yang harus diberikan pertolongan ketika membutuhkan bantuan dan/atau mengalami kesulitan baik dalam keadaan suka dan duka.

Kesadaran pentingnya sikap 'handep hapakat' salah satunya dalam pelaksanaan ritus upacara kematian penganut Hindu Kaharingan itu 
sendiri. Mengingat peristiwa kematian membuat keluarga duka dirundung rasa kehilangan atas orang yang mereka kasihi dan sayangi maka perasaan tidak ingin melepaskan kepergian orang meninggal tersebut adalah hal yang lumrah dialami keluarga duka yang ditinggalkan. Kematian akan melanda siapa saja tidak peduli kaya atau miskin. Ketika peristiwa kematian terjadi yang tidak diketahui kapan waktunya, tentu membuat keluarga tidak dipenuhi persiapan yang matang melaksanakan prosesi upacara kematian sesuai keyakinan yang dianutnya. Oleh karena itu, sebagai keluarga, kerabat, tetangga bahkan orang hidup yang tinggal dekat dengan keluarga duka sudah tentu apabila mendengar berita kematian maka dengan berbondong-bondong datang melayat ke rumah duka untuk meringankan beban keluarga duka. Secara spontan dengan hati yang penuh belas kasih datang turut serta berduka cita, memberi dukungan baik secara materil maupun moril, turut membantu tanpa harus diundang.

Rangkaian pelaksanaan upacara kematian penganut Hindu Kaharingan memberikan beban dan tanggung jawab moril bagi keluarga duka. Salah seorang informan, Gaya menjelaskan bahwa:

Bagi suku Dayak Ngaju penganut Hindu Kaharingan pelaksanaan ritus upacara kematian terdiri dari beberapa tahapan. Upacara kematian adalah untuk menghantarkan Liau Haring Kaharingan agar dapat menyatu dengan Ranying Hatalla. Terlaksananya rangkaian upacara kematian membutuhkan biaya, waktu dan tenaga. Sehingga kerabat, keluarga jauh, tetangga ataupun masyarakat disekitar umumnya ketika mendengar ada salah seorang penganut Hindu Kaharingan/atau umat yang beragama lain meninggal dunia juga turut serta menanamkan sikap 'handep hapakat', sikap tolongmenolong, saling membantu, bergotong royong membantu sesamanya yang sedang dirundung duka cita. Bahkan sikap 'handep hapakat' tidak hanya pada saat upacara kematian, juga berlaku ketika upacara perkawinan, hajatan, kegiatan masyarakat, bahkan di masa lampau ia juga menjelaskan bahwa sikap 'handep hapakat' berlaku apabila di antara masyarakat ada yang membangun rumah tempat tinggal. (Hasil wawancara, 15 November 2018).

Wujud sikap 'handep' yang ditunjukkan masyarakat suku Dayak Ngaju di Kalimantan Tengah diketahui memang sudah menjadi kebiasaan sejak lama dan diwariskan secara turun-temurun yang sudah mengakar di seluruh lapisan masyarakat. Ketika terjadi 'handep hapakat' biasanya 
d i a w a l i

$\mathrm{d}$ e $\mathrm{n} \mathrm{g}$ a $\mathrm{n}$

musyawarah/mupakat diantara keluarga satu dengan keluargakeluarga lainnya bahkan dapat terjadi dalam komunitas masyarakat dalam suatu wilayah desa ketika hendak melangsungkan suatu upacara, hajatan, gotong royong dan sebagainya. Dalam musyawarah tersebut satu sama lainnya akan berbagi tugasnya masing-masing. Kemudian, di kemudian hari akan saling membalas kebaikan yang pernah dilakukan.

Sosial kemasyarakatan secara konsepsional memiliki ciri-ciri untuk mengutamakan kepentingan bersama di atas kepentingan pribadi. Serangkaian aktivitas yang memungkinkan terjalinnya kerjasama termasuk ke dalam hubungan sosial kemasyarakatan 'Handep Hapakat'. Dengan demikian, maka aktualisasi pada pelaksanaan ritus upacara kematian penganut Hindu Kaharingan memiliki nilai-nilai luhur yang perlu diwariskan sebagai berikut.

Pertama, nilai religius. Sikap 'handep hapakat' saat warga penganut Hindu Kaharingan meninggal merupakan suatu keharusan di mana mendorong setiap orang yang masih hidup untuk tetap menjaga tali silahturami antara sesamanya. Ketika suatu kematian menimpa salah seorang keluarga maka dengan sendirinya keluarga lain atau masyarakat akan turut serta menghadiri pelaksanaan upacara kematian tersebut. Mereka saling berbagi kedukaan karena langsung hadir sebagai tanda ada ikatan batin antara satu dengan yang lainnya semakin kuat sebagai sesama makluk ciptaan Tuhan yang kelak akan mengalami kematian juga. Orang yang datang melayat dari waktu almarhum meninggal sampai kepada waktu penguburan hingga terlaksana ritusritus upacara kematian selanjutnya, dan berakhir dengan prosesi upacara kematian tingkat terakhir bermakna bahwa Liau Haring Kaharingan (almarhum yang meninggal) dapat didoakan oleh orang banyak agar cepat mencapai kebahagiaan sejati (niskala) untuk menyatu dengan Ranying Hatalla di Lewu Tatau Dia Rumpang Tulang, Rundung Raja Isen Kamalesu Uhate, Lewu Tatau Habaras Bulau, Habusung Hintan Hakarangan Lamiang.

Kedua, nilai gotong royong. Kehadiran keluarga, kerabat, rohaniwan, tetangga bahkan orang hidup yang tinggal dekat dengan keluarga duka mulai dari saat datang melayat saat waktu almarhum meninggal sampai kepada 
terlaksananya ritus-ritus upacara kematian selanjutnya, sebagian dari mereka turut mengambil bagian dalam persiapan sarana dan prasarana, prosesi penguburan, pembuatan peti jenazah hingga tahapan-tahapan selanjutnya berakhir. Peran semua pihak mulai dari prosesi awal upacara kematian hingga tahap terakhir kehadiran keluarga, kerabat dan handai taulan s a ngat diharapkan untuk meringankan beban keluarga duka.

Adapun menurut Kartodijo (1987) menyatakan sikap gotong royong merupakan budaya yang telah tumbuh dan berkembang dalam kehidupan sosial masyarakat Indonesia sebagai warisan budaya yang telah eksis secara turuntemurun. Oleh karena itu, adanya keterlibatan kerabat, rohaniwan, tetangga dan masyarakat sekitar dalam persiapan hal-hal sebagaimana di atas menunjukan adanya sikap gotong royong. Setiap individu yang memegang prinsip dan memahami roh gotong royong secara sadar bersedia dan sukarela sebagai bagian kelompok sosial masyarakat ikut meringankan beban keluarga duka yang ditinggalkan, dengan dilandasi semangat keihklasan, kerelaan, kebersamaan, toleransi dan kepercayaan. Kehadiran para pelayat yang datang memberi penghiburan, penguatan dan mendoakan almarhum yang meninggal serta merta meringankan beban keluarga duka. Sebaliknya kelak ketika ada keluarga lain yang telah memberi bantuan pada keluarga duka dan membutuhkan bantuan, maka akan dibalas kembali pemberian tersebut sebagai hubungan timbal balik.

Ketiga, nilai kekeluargaan. Pada saat ada keluarga yang meninggal, maka keluarga yang jauh maupun dekat akan hadir. Peristiwa kematian memicu rasa kemanusiaan dari semua pihak, lebih-lebih untuk keluarga yang memiliki ikatan darah. Mereka akan merasa senasib dan sepenanggungan untuk menghadapi peristiwa yang dialami keluarga duka. Oleh karenanya, rasa kekeluargaan yang timbul akibat jalinan peristiwa kedukaan perlu dipelihara dan ditumbuh-kembangkan dari generasi ke generasi.

Keempat, nilai solidaritas. Pelaksanaan ritus kematian penganut Hindu Kaharingan dari tahap awal hingga tahap terakhir bukanlah proses yang singkat. Sebagai contoh, pada saat sebelum dan sesudah penguburan biasanya diadakan Basarah Ampung, maka keluarga besar dan handai taulan akan 'handep hapakat' memberikan waktu, tenaga, 
dan materi mereka dalam keadaan berduka tersebut. Bahkan terkadang keluarga yang lain merasa ada tanggung jawab dan beban moril agar pelaksanaan upacara kematian untuk menghantarkan almarhum yang meninggal dunia bisa berjalan dengan baik dan lancar. Rasa kebersamaan dari semua yang turut hadir dan membantu baik yang datang dari berbagai kelompok dan golongan menjadikan merasa bersatu dalam satu ikatan keluarga duka.

Kelima, nilai musyawarah mupakat. Dalam musyawarah mufakat sesungguhnya harus dikedepankan nilai-nilai yang terkandung di dalam musyawarah tersebut. Misalnya, saling menghargai pendapat seorang dengan orang lain. Menghargai perbedaan pendapat setiap individu, pada saat musyawarah yang selalu diselesaikan dengan musyawarah. Mengingat prosesi pelaksanaan ritus upacara kematian penganut $\mathrm{Hindu}$ Kaharingan membutuhkan biaya dan tenaga maka keluarga duka beserta keluarga besar dan handai taulan bahu-membahu, saling berbagi beban moril dan tanggung jawab untuk melancarkan terselenggaranya upacara tersebut. Mereka juga merembug setiap persiapan saranaprasarana serta rencana yang akan dilaksanakan demi lancarnya prosesi upacara kematian tersebut dari tahap awal hingga ke tahap terakhir nantinya. Keluarga duka tentunya memperoleh keringanan dalam menghadapi beban yang sedang terjadi.

\section{Simpulan}

Kematian akan terjadi pada setiap insan yang hidup. Menyadari hal tersebut Hindu Kaharingan mengajarkan umatnya untuk mengamalkan sikap 'handep hapakat' baik dalam keadaan suka maupun duka. Aktualisasi nilai-nilai 'handep hapakat' sebagai wujud kebersamaan, dalam sikap saling tolong-menolong, bahu-membahu, gotong royong, musyawarah/mupakat sangat diperlukan dan harus dipraktikkan baik oleh perorangan maupun sekelompok masyarakat di kehidupan sosial kemasyarakatannya.

Menghadapi tantangan globalisasi dan modernisasi yang mendera zaman kekinian tentu dalam melaksanakan praktik keagamaan maka sikap 'handep hapakat' perlu diinternalisasikan dalam kehidupan keseharian. Mengingat kemajuan modernisasi yang tidak bisa dihindari, dimana kepentingan pribadi lebih diutamakan dibandingkan kepentingan kelompok dan golongan 
Jurnal Penerangan Agama Hindu Vol. 16 No. 2, 2018 
yang membuat manusia mengarah

pada paham individualisme, egoisme, dan materialisme, yang mengikis sikap simpati menjadi antipati. Hal ini te $\mathrm{ntu}$ bertentangan dengan pengamalan ajaran agama Hindu Kaharingan secara khusus yang mengutamakan 'penyang hinje simpei, paturung umba tamburak' (bersatu padu mencapai tujuan hidup) baik secara lahiriah dan batiniah.

Dengan demikian, alangkah baiknya tantangan kemajuan jaman dan globalisasi menjadi tantangan baru dalam mempuk nilai-nilai yang te $\mathrm{rkan} \mathrm{d} \mathrm{u} \mathrm{g}$ da la m s o s i a l kemasyarakatan 'handep hapakat' diantaranya nilai religius, nilai gotong royong, nilai kekeluargaan, nilais o li d a r i t a s, d a n n i l a imusyawa rah / mupakat. Penulis berkesimpulan bahwa ciri khas ajaran penganut Hindu Kaharingan memberi karakteristik tersendiri yang senada dengan ajaran agama-agama global yang mengajarkan kerukunan hidup baik di dunia dan di akhirat.

\section{DAFTAR PUSTAKA}

Haryanto, Sindung. 2015. Sosiologi Agama Dari Klasik Hingga Postmodern. Yogyakarta: Ar- Ruzz Media.

Iper, Dunis. 2009. Kamus Bahasa Dayak Ngaju-Indonesia. Palangka Raya: Anugerah 
Jurnal Penerangan Agama Hindu Vol. 16 No. 2, 2018 